\title{
Produção de lodo e comportamento químico de sais de ferro empregados no pós-tratamento de esgoto sanitário por precipitação química
}

\section{Sludge production and chemical behavior of iron salts employed in the post-treatment of sanitary wastewater by chemical precipitation}

\author{
Sidney Seckler Ferreira Filho \\ Engenheiro Civil pela Escola Politécnica da Universidade de São Paulo (EPUSP). Professor-associado do Departamento de Engenharia Hidráulica \\ e Sanitária da EPUSP
}

André Luiz Marguti

Aluno de Graduação do Curso de Engenharia Ambiental pela EPUSP

Roque Passos Piveli

Engenheiro Civil pela Escola de Engenharia de São Carlos (EESC). Professor-associado do Departamento de Engenharia Hidráulica e Sanitária da EPUSP

\begin{abstract}
Resumo
A combinação de processos físico-químicos e biológicos no tratamento de esgotos sanitários tem se apresentado como uma alternativa na remoção de fósforo. No entanto, uma das limitações é a sua maior produção de lodo. Desse modo, este trabalho teve por objetivo avaliar a produção de lodo resultante da aplicação de sais de ferro para diferentes tipos de efluentes, bem como estudar o impacto de sua aplicação nas características físico-químicas dos efluentes estudados. Concluiu-se que os valores médios de produção de lodo resultante da formação do hidróxido férrico situaram-se em torno de 1,80; 1,95 e 1,34 mg lodo/mg Fe+3 para esgoto bruto, efluente aeróbio e anaeróbio tratado, respectivamente, indicando que as características da fase líquida não influenciaram os mecanismos de precipitação dos íons férricos.
\end{abstract}

Palavras-chave: precipitação química; alcalinidade; produção de lodo; remoção de fósforo; tratamento de esgotos sanitários.

\begin{abstract}
The combination of physical-chemical and biological processes in sanitary wastewater treatment has been employed as an alternative for phosphorus removal; however, one of its limitations is its large sludge production. This work aimed at evaluating the sludge production which resulted from iron salt application to different types of effluents, as well as studying the impacts of iron salt application on the physical-chemical characteristics of the studied effluents. It was concluded that the average sludge production values which resulted from ferric hydroxide formation were around $1.80,1.95$ and 1.34 mg sludge per mg of Fe ${ }^{+3}$ ion, with regard to raw wastewater, aerobic treated effluent and anaerobic treated effluent, respectively, thus indicating that the liquid phase characteristics did not influence the ferric ion precipitation mechanisms.
\end{abstract}

Keywords: chemical precipitation; alkalinity; sludge production; phosphorus removal; wastewater treatment.

\section{Introdução}

Tradicionalmente, o tratamento de esgotos tem sido composto por processos biológicos, podendo eles ser anaeróbios, aeróbios ou uma combinação de ambos. No entanto, em função do estabelecimento de padrões mais restritivos de qualidade de corpos d'água e de lançamento de efluentes em corpos receptores, a adoção de processos físico-químicos combinados com biológicos objetivando a remoção de fósforo, tem tido uma elevada aceitação como concepção de estações de tratamento de esgotos.

A remoção de fósforo no tratamento de esgotos pode ocorrer por via biológica ou por precipitação química mediante o emprego de sais de alumínio ou ferro. Além da eficiência de remoção elevada, uma vantagem da aplicação de processos físico-químicos de remoção de fósforo em relação aos biológicos é a sua grande flexibilidade, podendo ser facilmente adaptados em unidades já 
existentes ou quando do projeto de sistemas de tratamento a serem implantados. Os processos biológicos, por sua vez, tendem a apresentar uma maior complexidade operacional por serem altamente dependentes do comportamento da biomassa ativa, das condições ambientais previstas no reator e das características do substrato afluente (MARAIS, 1983; MULKERRINS; DOBSON; COLLERAN, 2004).

Portanto, a utilização de processos físico-químicos de remoção de fósforo tem sido vista como alternativa tecnológica bastante promissora, podendo estes ser empregado de forma isolada ou conjunta a processos biológicos. O uso de processos de precipitação química em combinação com processos biológicos de tratamento oferece bastante flexibilidade com respeito à remoção de fósforo, uma vez que é possível controlar a eficiência do processo de remoção de fósforo, independentemente das condições de operação dos processos biológicos de tratamento.

Embora não seja uma alternativa muito comum, a aplicação de coagulantes metálicos pode ser efetuada na entrada dos decantadores primários e, nesse caso, os objetivos da combinação de processos de precipitação química conjuntamente com o processo biológico se estendem além da necessidade de remoção de fósforo. Uma vez que parte da carga orgânica afluente à Estação de Tratamento de Esgoto (ETE) tenderá a ser removida quando adicionado o coagulante metálico, haverá uma diminuição da demanda bioquímica de oxigênio (DBO) afluente ao sistema biológico, o que torna a concepção do processo físico-químico combinado ao processo biológico atrativa para sistemas em que há uma significativa variação temporal da carga orgânica ao processo de tratamento.

Os sistemas de coleta e afastamento de esgotos sanitários localizados em regiões litorâneas e turísticas são alguns exemplos de locais onde se torna atrativa a aplicação de sistemas dessa natureza, pois em épocas de maior vazão e carga orgânica afluente ao sistema de tratamento de esgotos, a aplicação de coagulantes metálicos permite não somente a remoção de fósforo do efluente final, como também reduz a carga orgânica afluente ao processo biológico de tratamento, evitando, desse modo, que o mesmo tenha que ser dimensionado para atendimento da carga orgânica em épocas de maior população fixa e flutuante. Algumas aplicações dessa combinação de processos de tratamento já se encontram em operação, podendo-se citar a Riviera de São Lourenço, localizado no Litoral Sul do Estado de São Paulo, como um exemplo de sucesso.

A clássica combinação de processos biológicos de tratamento com processos físico-químicos se dá quando este é empregado a jusante do processo biológico de tratamento, podendo, inclusive, ser um processo biológico anaeróbio ou aeróbio. Quando o processo físico-químico é empregado a jusante de processos biológicos aeróbios, é denominado processo terciário de tratamento e a sua principal função é a remoção de fósforo unicamente, uma vez que a remoção de carga orgânica já ocorreu de forma satisfatória no processo biológico aeróbio. No Brasil, a construção de sistemas terciários de tratamento de esgotos não é comum, em face de seus altos custos de implantação e operação, sendo a cidade de Brasília uma das poucas que contêm ETE compostos por processos terciários de tratamento.

No entanto, quando o processo físico-químico é implantado a jusante de processos anaeróbios de tratamento, objetiva-se garantir não somente a remoção de fósforo, mas também efetuar um polimento da qualidade do efluente do processo biológico, dado que a remoção de carga orgânica unicamente por processos anaeróbios de tratamento é limitada em torno de 60 a 70\% da carga orgânica afluente ao sistema de tratamento, o que impede que o efluente de processos anaeróbios de tratamento possam ser lançados em corpos receptores. A concepção de processos de precipitação química associada a processos anaeróbios vem sendo objeto de inúmeras pesquisas, sendo que Santos (2006) reporta inúmeras aplicações já em escala real, podendo-se citar as ETEs dos municípios de Campinas, Valinhos, Rio Claro e Barra Bonita.

Para os casos em que a ETE já se encontra implantada e não há condições de implantação de sistemas terciários para a remoção de fósforo, pode-se efetuar a aplicação de coagulantes metálicos ou na entrada do processo biológico de tratamento ou a montante dos decantadores secundários. Desse modo, garante-se a possibilidade de combinação de processos físico-químicos com processos biológicos sem que haja a necessidade de implantação de unidades adicionais de tratamento.

A aplicação de processos físico-químicos combinados a processos biológicos no tratamento de esgotos sanitários requer um sistema de controle de dosagem de produtos químicos que possibilite a correta operação dos processos de precipitação química de fósforo e que permita a otimização da aplicação do coagulante, devendo ser ressaltada a necessidade de minimização das suas dosagens e estabelecimento de faixas de operação adequada do pH da fase líquida. Assim sendo, o conhecimento das variações temporais das principais características físico-químicas do efluente a ser tratado, bem como a capacitação técnica das equipes de operação das ETEs que contemplem processos físico-químicos é de vital importância, de modo que a sua aplicação possa ser otimizada.

Independentemente do modo como os processos de precipitação química possam ser combinados com os processos biológicos, uma das maiores restrições aos processos físico-químicos diz respeito ao aumento da produção de lodo, que pode sobrecarregar as unidades de tratamento da fase sólida bem como elevar os custos de transporte e disposição final.

Considerando-se que os atuais custos de transporte e disposição final de resíduos sólidos gerados em ETAs e ETEs têm se situado em torno de R\$ 100 e R \$ 150,00 por tonelada em regiões metropolitanas, faz-se de suma importância a correta avaliação da produção de lodo em processos físico-químicos empregados no tratamento de 
esgotos sanitários, de modo que seja possível efetuar uma análise econômica, cotejando-se as principais tecnologias de tratamento que possam atender aos padrões de qualidade e de emissão preconizados pela legislação brasileira.

O objetivo deste trabalho foi estudar a aplicabilidade de processos físico-químicos de precipitação química, com o uso de sais de ferro como coagulantes, ao processo de tratamento de esgotos, pretendendo-se mais especificamente:

- estudar o impacto da aplicação de processos de precipitação química nas características físico-químicas dos efluentes estudados, mais especificamente em sua capacidade de tamponamento e $\mathrm{pH}$ da fase líquida;

- avaliar a produção de lodo seco resultante da aplicação de coagulantes à base de sais de ferro para diferentes tipos de efluentes.

\section{Material e métodos}

Com o objetivo de permitir a avaliação da produção de lodo e respectivas características que possam causar impacto em suas operações subsequentes de adensamento e desidratação, a pesquisa foi desenvolvida tendo-se empregado três diferentes tipos de efluentes:

- esgoto gradeado e desarenado afluente aos decantadores primários da ETE Barueri, sendo do tipo lodos ativados convencional (Esgoto Bruto Barueri);

- efluente final produzido pela ETE Barueri (Efluente Final Barueri);

- esgoto tratado produzido pela ETE Ribeirão Pires, do tipo tratamento anaeróbio, por reatores UASB (Upflow Anaerobic Sludge Blanket - Efluente Final RP).

Ambas as ETEs estão localizadas na Região Metropolitana de São Paulo (SP) e são operadas pela Companhia de Saneamento Básico do Estado de São Paulo (Sabesp). Foram escolhidas por permitirem avaliar o comportamento de diferentes tipos de esgotos sanitários quando submetidos a processos de precipitação química e, desse modo, estimar a produção de lodo seco mediante o emprego de coagulação química. Uma vez que se espera que a precipitação de sais de ferro apresente comportamento distinto para as diferentes águas residuárias, pretendeu-se avaliar o comportamento destas quando submetidas a processos de precipitação química, enfocando-se o comportamento e os efeitos do coagulante nas características físico-químicas do efluente, bem como em sua produção de lodo.

A ETE Ribeirão Pires possui uma vazão média de 40 L/s e sua concepção é do tipo tratamento anaeróbio composto por reatores UASB. O tratamento preliminar é composto por unidades de gradeamento mecanizado e desarenação por meio de caixa de areia aerada, sendo o efluente posteriormente encaminhado para quatro reatores UASB que operam em paralelo. Como a ETE foi concebida sendo composta unicamente por um sistema de tratamento anaeróbio, o efluente final é posteriormente encaminhado para o corpo receptor.

A ETE Barueri é do tipo lodo ativado convencional, apresentando uma vazão média de $9,0 \mathrm{~m}^{3} / \mathrm{s}$. A execução dos ensaios experimentais com o esgoto bruto e tratado proveniente da ETE Barueri possibilitou avaliar a possibilidade de otimização de processos de remoção de nutrientes por sistemas de tratamento em que o coagulante possa ser adicionado diretamente no tanque de aeração ou em unidades complementares a jusante do sistema biológico aeróbio (tratamento terciário).

Os efluentes bruto e tratado da ETE Barueri empregados na investigação foram coletados a jusante da caixa de areia aerada e após os decantadores secundários, respectivamente. Por sua vez, o efluente tratado proveniente da ETE Ribeirão Pires foi coletado diretamente nas calhas de coleta dos reatores UASB. Os mesmos foram coletados e dispostos em bombonas com capacidade de 20 L cada, sendo coletado um volume mínimo de 40 L por amostragem para fins de execução dos ensaios experimentais. Imediatamente após a sua coleta, os volumes eram conduzidos ao Laboratório de Saneamento Professor Lucas Nogueira Garcez para posterior caracterização físico-química. As principais variáveis físico-químicas adotadas para a caracterização dos efluentes foram $\mathrm{pH}$, carbono orgânico dissolvido (COD), alcalinidade, SST, nitrogênio orgânico e amoniacal, fósforo total e suas respectivas frações. Todas as análises foram efetuadas de acordo com APHA/AWW/WEF (2005).

Os ensaios experimentais foram conduzidos em escala de jartest, tendo-se empregado o cloreto férrico como coagulante. A escolha pelo sal de ferro como coagulante é justificada pelo fato de este permitir a formação de flocos mais densos e com velocidades maiores de sedimentação quando comparado a sais de alumínio. Além disto, ressalta-se que as ETEs recentemente projetadas e que possuem processos físico-químicos objetivando a remoção de fósforo foram concebidas para trabalharem com sais de ferro em função de sua melhor adequação de uso no tratamento de esgotos (SINELLI, 2002).

Anteriormente a cada ensaio de jar-test, foram executadas as curvas de titulação de cada efluente, empregando-se como titulante o cloreto férrico empregado nos ensaios de avaliação de produção de lodo. Dessa forma, transferiu-se $1 \mathrm{~L}$ de amostra para um becker de mesma capacidade e efetuou-se o monitoramento do $\mathrm{pH}$ da fase líquida mediante adição de volumes pré-definidos de solução de coagulante preparada com concentração igual a $10 \mathrm{~g} / \mathrm{L}$ de de $\mathrm{FeCl}_{3}$. As dosagens de coagulante foram variadas de $10 \mathrm{mg} / \mathrm{L}$ a $300 \mathrm{mg} / \mathrm{L}$, com vistas a possibilitar avaliar o comportamento da fase líquida para diferentes dosagens de coagulante eventualmente passível de serem utilizadas em processos de precipitação química objetivando a remoção de fósforo.

Para cada ensaio de jar-test executado, foi mantida fixa a faixa de $\mathrm{pH}$ de coagulação para cada um dos jarros, tendo-se variado a 
dosagem de cloreto férrico de $10 \mathrm{mg} / \mathrm{L}$ a $300 \mathrm{mg} / \mathrm{L}$. O pH de coagulação foi ajustado em cada um dos jarros mediante adição de volumes de base, de modo que estivesse situado entre 6,0 a 6,5, faixa esta considerada ótima para a precipitação de fósforo por intermédio da aplicação de sais de ferro como coagulante (BENJAMIN, 2002). As soluções de coagulante e base utilizadas na condução dos ensaios eram confeccionadas diariamente, sendo que a solução de cloreto férrico e base eram preparadas com concentração igual a 10 ou 20 g $\mathrm{FeCl}_{3} / \mathrm{L}$ e 1,0 M, respectivamente.

Os procedimentos adotados para a execução dos ensaios experimentais envolveram inicialmente a transferência de um volume de 2 L de amostra para cada um dos jarros do equipamento de jar-test. Em seguida, a rotação do sistema de agitação era ajustada para cerca de $300 \mathrm{rpm} \mathrm{e}$, imediatamente, era efetuada a adição do coagulante e base para a eventual correção do seu pH de coagulação. A quantificação dos volumes de base requeridos para a correção do pH de coagulação foi determinada mediante a execução de curvas de titulação específicas para cada amostra e respectiva dosagem de coagulante imediatamente antes da execução dos ensaios de jar-test. Após 30 segundos de mistura rápida, a rotação era reduzida para $40 \mathrm{rpm}$ e procedia-se à etapa de floculação, considerando-se um tempo de mistura lenta igual a dez minutos. Após cinco minutos de mistura lenta, efetuava-se a coleta de amostras para a execução das análises de SST mediante a sua filtração em membrana Whatman GF/C, sendo que após dez minutos o equipamento era desligado e encerrava-se o ensaio experimental.

Os parâmetros considerados na execução dos ensaios de jar-test foram adotados e não foram variados, uma vez que não se objetivava a otimização de parâmetros de mistura rápida, floculação e sedimentação. Enfocaram-se os aspectos químicos envolvidos na interação entre o coagulante e a fase líquida e a sua produção de lodo. Assim, os resultados experimentais produzidos puderam ser comparados entre si, pois do ponto de vista metodológico, as condições operacionais sempre foram mantidas constantes.

\section{Apresentação e análise dos resultados}

As Figuras 1 a 3 apresentam as curvas de titulação típicas obtidas para os efluentes empregados na investigação experimental em função da dosagem de coagulante.

Em função do caráter ácido do cloreto férrico quando empregado como coagulante, espera-se que, com o aumento de sua dosagem na fase líquida, ocorra uma diminuição do seu valor de $\mathrm{pH}$, devendo este ser controlado de modo que a remoção de fósforo e o controle da solubilidade do ferro na fase líquida possam ser ajustados para suas condições ótimas de operação. Os resultados apresentados nas Figuras 1 a 3 evidenciam esse comportamento, sendo que as variações de $\mathrm{pH}$ na fase líquida apresentaram-se variáveis, sendo esta função do tipo de efluente empregado e seu respectivo valor de alcalinidade inicial.

Observando-se os resultados experimentais apresentados na Figura 1, nota-se que o Esgoto Bruto Barueri apresentou valores de alcalinidade inicial que variaram de $240 \mathrm{mg} \mathrm{CaCO} / \mathrm{L}$ a $430 \mathrm{mg}$ $\mathrm{CaCO}_{3} / \mathrm{L}$, valores típicos de esgotos sanitários não-tratados. Percebese que a depleção do $\mathrm{pH}$ da fase líquida quando da adição do coagulante foi menos significativa quanto maior o valor da alcalinidade inicial, o que era de se esperar, uma vez que a capacidade de tamponamento e resistência à mudança no $\mathrm{pH}$ da fase líquida tende a ser mais intensa quanto menor os seus valores de alcalinidade. $\mathrm{O}$ mesmo comportamento do Esgoto Bruto Barueri foi observado para o Efluente Tratado Barueri e Ribeirão Pires, tendo-se tão somente variado de intensidade em função dos seus respectivos valores de alcalinidade e $\mathrm{pH}$ iniciais.

No entanto, o aspecto mais significativo com respeito ao comportamento químico do ferro como coagulante em processos de precipitação química de fósforo em esgotos sanitários está relacionado aos parâmetros da dosagem de coagulante requerida, $\mathrm{pH}$ e alcalinidade inicial. De acordo com evidências experimentais (SNOEYINK; JENKINS, 1980; SEDLAK, 1991), as dosagens que podem ser consideradas ótimas para a remoção de fósforo em esgotos sanitários situam-se em torno de $60 \mathrm{mg} \mathrm{FeCl} / \mathrm{L}$ a $100 \mathrm{mg}$ $\mathrm{FeCl}_{3} / \mathrm{L}$, o que corresponde a uma relação molar mínima entre Fe e $\mathrm{P}$ da ordem de 2:1 a 3:1.

Para efluentes que apresentam elevada alcalinidade inicial, tipicamente esgotos sanitários brutos, a aplicação de dosagens de coagulante em concentrações que permitam uma remoção eficiente de fósforo, não tenderão a comprometer a eficiência do processo de precipitação química de fósforo, uma vez que os valores de $\mathrm{pH}$ da fase líquida tenderão a situar-se acima de 6,0. Do ponto de vista prático, isso significa que não deverá ser necessária a adição de alcalinizante conjuntamente com o coagulante para fins de correção do pH da fase líquida, embora essa avaliação tenha que ser cuidadosamente efetuada em função das características do pós-tratamento, especialmente se forem concebidos como processos biológicos de tratamento, pois necessitam de condições ambientais ótimas para a sua operação.

Considerando-se a adoção de sistemas de tratamento em que a dosagem de coagulante é efetuada no efluente final do tratamento biológico, uma vez que os seus valores de alcalinidade inicial tenderão a serem reduzidos quando comparado aos efluentes em estado bruto, um cuidado especial tem de ser observado em relação à necessidade ou não de correção do pH da fase líquida quando da adição do coagulante.

Observando-se os resultados experimentais apresentados na Figura 2, nota-se que os valores de alcalinidade inicial para o Efluente Tratado Barueri são menores do que os do Esgoto Bruto Barueri. Essas diferenças estão diretamente associadas ao modo como a ETE Barueri é operada, uma vez que, por ser do tipo lodos 
ativados do tipo convencional, pode ocorrer a nitrificação do esgoto com consumo de alcalinidade. Para o Esgoto Bruto Barueri coletado em dezembro de 2006, o valor de alcalinidade inicial foi $427 \mathrm{mg} \mathrm{CaCO} / \mathrm{L}$ e para o Efluente Tratado Barueri, $174 \mathrm{mg}$ $\mathrm{CaCO}_{3} / \mathrm{L}$. Essa significativa redução no valor da alcalinidade do esgoto bruto deve-se ao fato de que o processo de lodos ativados estava operando de modo a garantir a nitrificação do efluente, sendo que as suas concentrações afluentes e efluentes de nitrogê-

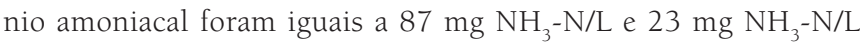
respectivamente, o que representa uma remoção de aproximadamente $74 \%$.

Por sua vez, para a coleta efetuada em abril de 2007, os respectivos valores de alcalinidade do esgoto bruto e efluente tratado foram iguais a $310 \mathrm{mg} \mathrm{CaCO}_{3} / \mathrm{L}$ e $255 \mathrm{mg} \mathrm{CaCO}_{3} / \mathrm{L}$, dosagens muito próximas entre si. Os valores de concentração de nitrogênio amoniacal para a mesma amostra foram iguais a $59 \mathrm{mg} \mathrm{NH}_{3}-\mathrm{N} / \mathrm{L}$ e $44 \mathrm{mg} \mathrm{NH}$ $\mathrm{N} / \mathrm{L}$ respectivamente, o que possibilitou uma remoção de somente $25 \%$. Essa baixa remoção de nitrogênio amoniacal foi a principal responsável pela não redução significativa da alcalinidade do esgoto bruto e, dessa forma, conclui-se que o modo como a ETE é operada responde diretamente pela redução ou não da capacidade de tamponamento da fase líquida e consequente necessidade de se efetuar a correção do pH do efluente final caso seja submetido a processos físico-químicos de remoção de fósforo.

Considerando-se os resultados experimentais apresentados na Figura 2, nota-se que para as dosagens consideradas ótimas para uma remoção eficiente de fósforo por processos de precipitação química (60 $\mathrm{mg} \mathrm{FeCl}_{3} / \mathrm{L}$ a $100 \mathrm{mg} \mathrm{FeCl}_{3} / \mathrm{L}$ ), para valores de alcalinidade inferiores a $200 \mathrm{mg} \mathrm{CaCO}_{3} / \mathrm{L}$, o pH da fase líquida foi reduzido para valores inferiores a 6,0, o que requer que a operação de sistemas de precipitação química contemplem a adição de alcalinizante para um controle adequado do pH do efluente final, não somente a fim de que os mecanismos de remoção de fósforo possam ser otimizados mas também o atendimento aos padrões de emissão.

Considerando esse contexto e observando-se os resultados experimentais apresentados na Figura 3, nota-se que os valores de alcalinidade do Efluente Tratado Ribeirão Pires foram significativamente menores do que quando comparados ao Esgoto Bruto e ao Efluente Tratado Barueri, sendo que seus valores situaram-se em torno de 90 mg $\mathrm{CaCO}_{3} / \mathrm{L}$ a $130 \mathrm{mg} \mathrm{CaCO}_{3} / \mathrm{L}$. Assim sendo, as limitações na operação de processos de precipitação química objetivando a remoção de fósforo em processos anaeróbios de tratamento tornam-se significativas quando não são previstas unidades de aplicação de alcalinizantes juntamente com o coagulante.

Algumas aplicações de processos de precipitação química com sais de ferro, combinadas a processos anaeróbios de tratamento, têm considerado a possibilidade de aplicação do coagulante a montante e a jusante dos reatores UASB. Levando-se em conta as dosagens de coagulante passíveis de serem empregadas para que se

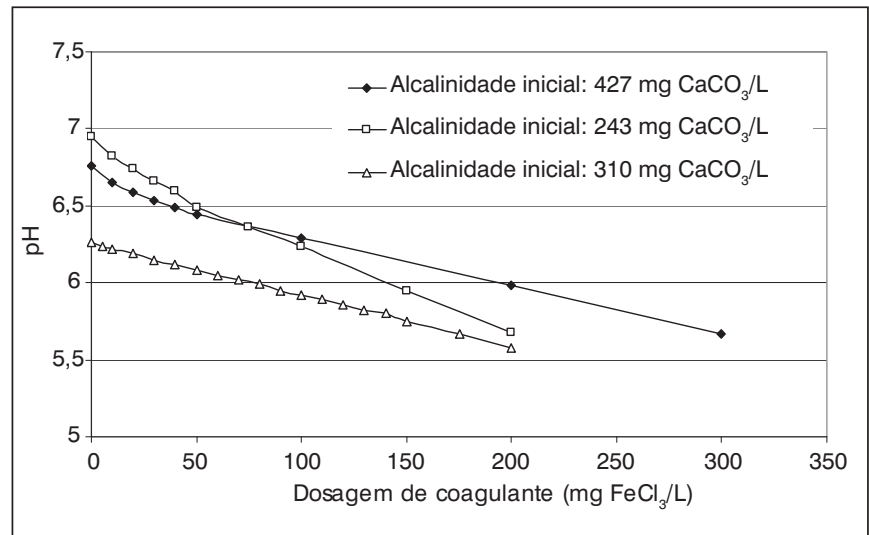

Figura 1 - Curva de titulação obtida para o Esgoto Bruto Barueri para diferentes valores de alcalinidade inicial

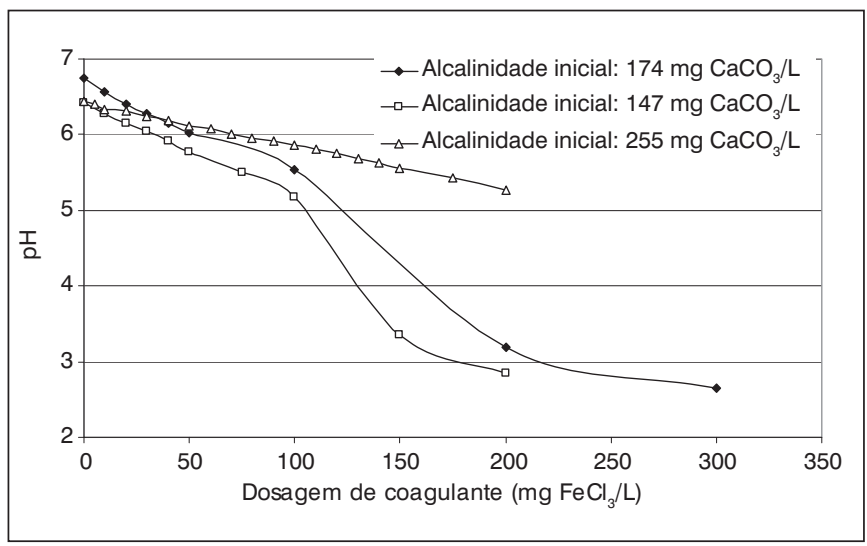

Figura 2 - Curva de titulação obtida para o Efluente Final Barueri para diferentes valores de alcalinidade inicial

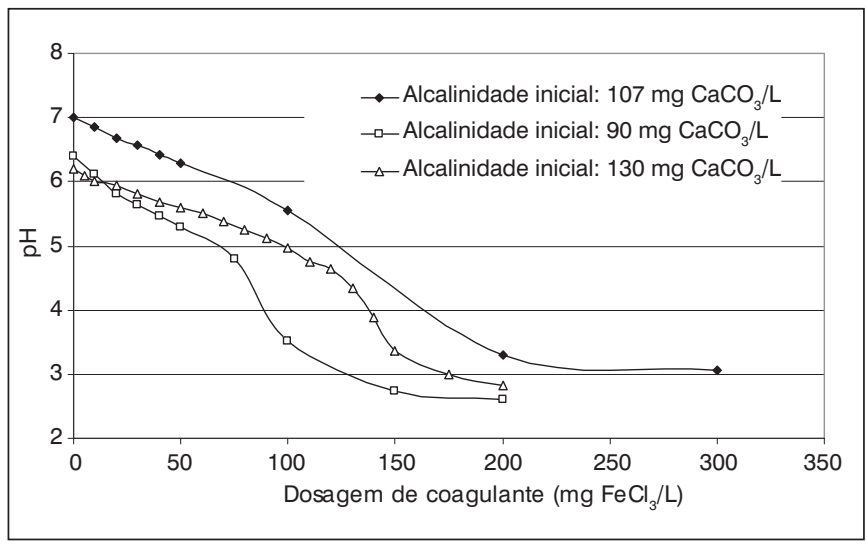

Figura 3 - Curva de titulação obtida para o Efluente Final Ribeirão Pires para diferentes valores de alcalinidade inicial

atinja uma eficiência adequada na remoção de fósforo e se assumam os baixos valores de alcalinidade observados para efluentes de processos anaeróbios, justifica-se a necessidade de implantação de sistemas de dosagem de alcalinizantes a fim de que seja possível a otimização dos processos de remoção de fósforo por mecanismos de precipitação química. 
Deve-se ressaltar que as dosagens de coagulante requeridas para uma efetiva remoção de fósforo também estão condicionadas à necessidade de produção de flocos formados por hidróxidos de ferro em uma condição que permita que as fases sólidas precipitadas possam ser eficientemente removidas por processos de separação sólido-líquido. Logo, é imprescindível que sejam previstos sistemas de aplicação de alcalinizante juntamente com o coagulante, pois em caso de necessidade operacional, pode-se manter as dosagens requeridas de coagulante a fim de que seja possível a plena otimização dos processos de remoção de fósforo e a manutenção do pH da fase líquida. Caso contrário, observa-se que, do ponto de vista operacional, se a alcalinidade do efluente for reduzida a um valor que, para uma específica dosagem de coagulante, reduza o pH da fase líquida abaixo de um determinado valor, a operação vê-se forçada a reduzir as dosagens de coagulante, podendo comprometer a eficiência do processo de precipitação química.

Considerando o comportamento de água natural, pode-se, mediante o uso de fundamentos de química aquática, avaliar o comportamento do pH da fase líquida para diferentes condições de alcalinidade e pH inicial e dosagem de coagulante. Assumindo a condição de eletroneutralidade da água pode-se escrever que:

$\sum$ Cátions $=\sum$ Ânions

Equação 1

Admitindo que o principal sistema ácido base responsável pela capacidade de tamponamento da fase líquida seja o sistema ácidocarbônico, pode-se escrever a Equação 1 da seguinte forma:

$\left(\sum \mathrm{C}_{\mathrm{P}}-\sum \mathrm{C}_{\mathrm{N}}\right)_{0}=\left[\mathrm{HCO}_{3}^{-}\right]+2 \cdot\left[\mathrm{CO}_{3}^{-2}\right]+\left[\mathrm{OH}^{-}\right]-\left[\mathrm{H}^{+}\right]$

Equação 2

$\left(\sum C_{P}-\sum C_{N}\right)_{0}=$ Somatória dos cátions e ânions associados

As concentrações de íons bicarbonato e carbonato podem ser expressos na forma de frações ionizáveis e, portanto, a Equação 2 pode ser escrita da seguinte forma:

$\left(\sum C_{P}-\sum C_{N}\right)_{0}=\left(\alpha_{1}+2 \cdot \alpha_{2}\right) \cdot C_{T}+\left[O H^{-}\right]-\left[H^{+}\right]$

Equação 3

onde:

$\mathrm{C}_{\mathrm{T}}$ : concentração de carbono inorgânico total (M);

$\alpha_{1}$ e $\alpha_{2}$ : frações ionizáveis do acido carbônico.

Quando há a adição do coagulante na fase líquida, sendo este um sal de ferro aplicado na forma de cloreto férrico, há a dissociação do sal na forma de íons ferro e íons cloreto. Como o ferro é altamente insolúvel na fase líquida, ele estará totalmente presente na forma precipitada, ou seja, na forma de hidróxido férrico. Por sua vez, o íon cloreto estará na forma dissolvida, devendo ser incorporado na Equação 3. Desse modo, temos: $\left(\sum C_{P}-\sum C_{N}\right)_{0}-\left[C l^{-}\right]=\left(\alpha_{1}+2 \cdot \alpha_{2}\right) \cdot C_{T}+\left[O H^{-}\right]-\left[H^{+}\right]$

Equação 4

Sabendo que a alcalinidade inicial da fase líquida está diretamente associada ao valor de $\left(\sum C_{P}-\sum C_{N}\right)_{0}$ e uma vez conhecido o seu valor de $\mathrm{pH}$ inicial, para diferentes valores de concentrações molares de íons cloreto pode-se calcular os valores de $\mathrm{pH}$ final da fase líquida. Dessa forma, empregando-se as Equações 1 a 4 e efetuando-se os cálculos para diferentes valores de $\mathrm{pH}$ e alcalinidade inicial da fase líquida, pode-se calcular os valores de $\mathrm{pH}$ final para diversos valores de dosagem de coagulante. Os valores calculados encontram-se apresentados nas Figuras 4 a 7 .

Observando-se os valores calculados de depleção do $\mathrm{pH}$ da fase líquida em função da dosagem de coagulante para diferentes valores de alcalinidade e pH inicial (Figuras 4 a 7), nota-se que, uma vez mantendo-se fixo um valor inicial de $\mathrm{pH}$, com a diminuição do valor da alcalinidade, há uma maior restrição da dosagem de coagulante passível de ser aplicada na fase líquida, considerando-se uma condição operacional em que o pH final não se situe abaixo de 6,0. Por exemplo, admitindo-se um valor de $\mathrm{pH}$ inicial igual a 6,5, as dosagens máximas de cloreto férrico passíveis de serem aplicadas na fase líquida a fim de que o $\mathrm{pH}$ final não seja reduzido para valores inferiores a 6,0 são da ordem de $50 \mathrm{mg} \mathrm{FeCl}_{3} / \mathrm{L}, 75 \mathrm{mg} \mathrm{FeCl} / \mathrm{L}, 100 \mathrm{mg}$ $\mathrm{FeCl}_{3} / \mathrm{L}$ e $152 \mathrm{mg} \mathrm{FeCl}_{3} / \mathrm{L}$ para valores de alcalinidade inicial iguais a $100 \mathrm{mg} \mathrm{CaCO} / \mathrm{L}, 150 \mathrm{mg} \mathrm{CaCO} / \mathrm{L}, 200 \mathrm{mg} \mathrm{CaCO} / \mathrm{L}$ e $300 \mathrm{mg}$ $\mathrm{CaCO}_{3} / \mathrm{L}$, respectivamente.

Desse modo, a fim de se garantirem as condições ótimas de remoção de fósforo, bem como de se permitir uma adequada operação dos sistemas de separação sólido-líquido considerando-se uma dosagem máxima de coagulante igual a 100 mg FeCl $/$ L, o mínimo valor de alcalinidade que não necessitará da dosagem de alcalinizantes será igual a $200 \mathrm{mg} \mathrm{CaCO} / \mathrm{L}$. Como nem sempre os valores de alcalinidade de efluentes que serão submetidos a processos de coagulação química possuem tais grandezas, especialmente efluentes tratados por processos biológicos aeróbios nos quais é considerada a operação de processos de nitrificação, torna-se de suma importância a necessidade de concepção de sistemas de dosagem de alcalinizantes, caso haja necessidade de sua aplicação para fins de correção do $\mathrm{pH}$.

A influência do pH inicial é também importante quando se consideram as dosagens de cloreto férrico máximas passíveis de serem aplicadas para os diferentes valores de alcalinidade. Assumindo um valor de pH inicial igual a 7,5, as dosagens máximas de cloreto férri$\mathrm{co}$, a fim de que o pH final não seja reduzido para valores inferiores a 6,0, são da ordem de $72 \mathrm{mg} \mathrm{FeCl} / \mathrm{L}, 108 \mathrm{mg} \mathrm{FeCl} / \mathrm{L}, 144 \mathrm{mg}$ $\mathrm{FeCl}_{3} / \mathrm{L}$ e $216 \mathrm{mg} \mathrm{FeCl}_{3} / \mathrm{L}$ para valores de alcalinidade inicial iguais a $100 \mathrm{mg} \mathrm{CaCO} / \mathrm{L}, 150 \mathrm{mg} \mathrm{CaCO} / \mathrm{L}, 200 \mathrm{mg} \mathrm{CaCO} / \mathrm{L}$ e $300 \mathrm{mg}$ $\mathrm{CaCO}_{3} / \mathrm{L}$, respectivamente. Desse modo, assumindo que o $\mathrm{pH}$ da fase líquida não pode sofrer uma depleção que faça com que o seu valor seja inferior a 6,0, temos que o valor de alcalinidade mínima limite 


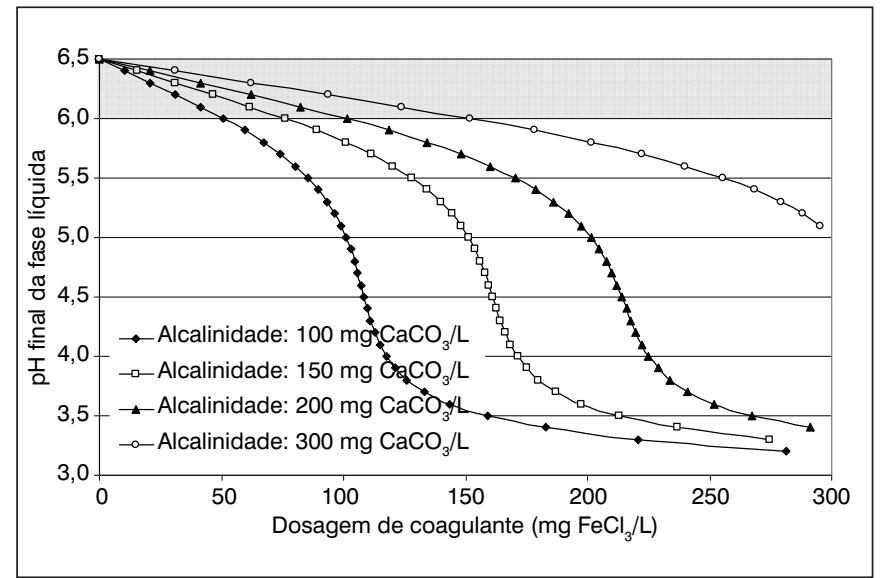

Figura 4 - Curva de titulação calculada para diferentes valores de alcalinidade: $\mathrm{pH}$ inicial $=6,5$

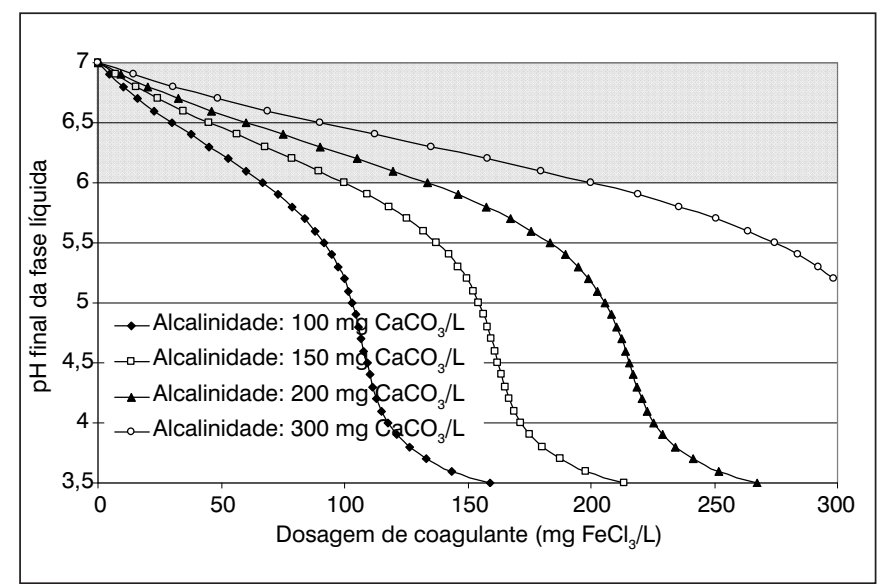

Figura 5 - Curva de titulação calculada para diferentes valores de alcalinidade, $\mathrm{pH}$ inicial $=7,0$

situa-se em torno de $150 \mathrm{mg} \mathrm{CaCO}_{3} / \mathrm{L}$, inferior quando comparado no caso de o pH inicial da fase líquida ser da ordem de 6,5.

Um dos aspectos mais importantes e nem sempre considerados de forma adequada no projeto de ETEs que possuem sistemas de remoção de fósforo por processos de precipitação química é a avaliação da produção de lodo seco oriunda da aplicação de sais de ferro. Uma vez que um dos principais custos associados à operação de ETEs que possuem sistemas de coagulação química envolve o seu tratamento, transporte e disposição final dos lodos gerados nas diferentes etapas do processo de tratamento, é de vital importância que sejam corretamente avaliados de modo que o cotejo econômico das diferentes alternativas de projeto possam ser consideradas.

A estimativa da produção de lodo seco originária pela precipitação do hidróxido férrico foi calculada mediante a determinação das concentrações de SST nos efluentes brutos e coagulados. De posse dos seus valores para os ensaios executados com diferentes dosagens de coagulante, a produção de lodo seco pôde ser calculada da seguinte forma:

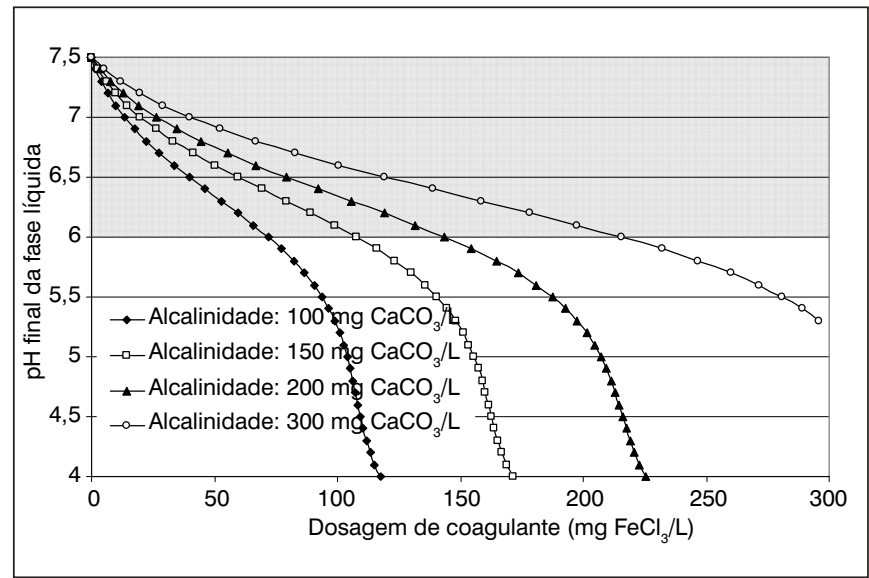

Figura 6 - Curva de titulação calculada para diferentes valores de alcalinidade, $\mathrm{pH}$ inicial $=7,5$

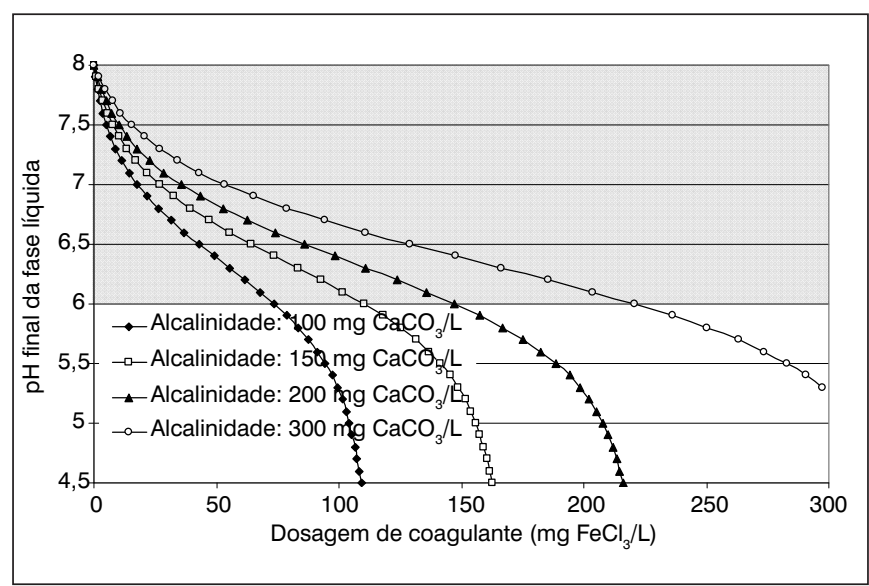

Figura 7 - Curva de titulação calculada para diferentes valores de alcalinidade, $\mathrm{pH}$ inicial $=8,0$

$P L=S S T_{A C}-S S T_{E B}$

Equação 5

onde:

PL: produção de lodo seco devido à formação do hidróxido metálico (mg/L);

$\mathrm{SST}_{\mathrm{AC}}$ : concentração de sólidos em suspensão total na efluente coagulado (mg/L);

$\mathrm{SST}_{\mathrm{EB}}$ : concentração de sólidos em suspensão total no efluente bruto (mg/L).

Sendo assim, as Figuras 8, 9 e 10 apresentam alguns resultados típicos de produção de lodo seco considerados para os diferentes efluentes empregados na investigação experimental para diversas dosagens de coagulante.

Considerando a estequiometria da precipitação do ferro na fase líquida, sabe-se que a totalidade dos íons ferro adicionados na forma de sais, podendo ser cloreto férrico ou sulfato férrico, tenderão a precipitar na forma de hidróxidos, uma vez que, para as faixas de $\mathrm{pH}$ usuais em que são controlados os processos de coagulação e floculação, a sua solubilidade é mínima. Portanto, pode-se escrever que: 


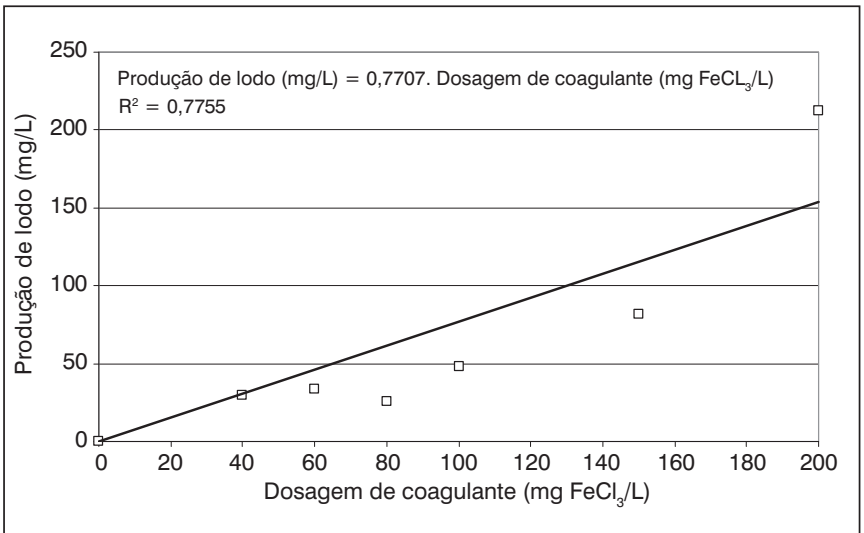

Figura 8 - Produção de lodo obtida para o Esgoto Bruto Barueri para diferentes valores de dosagens de coagulante

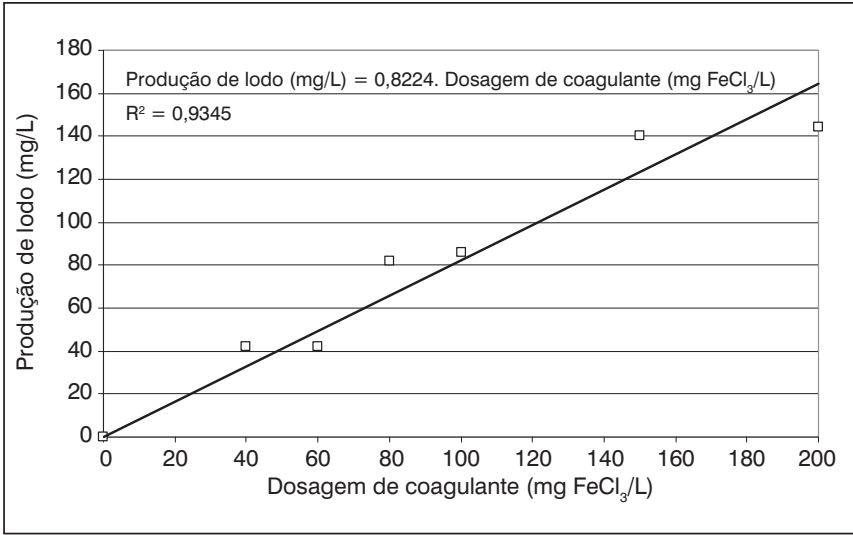

Figura 9 - Produção de lodo obtida para o Efluente Final Barueri para diferentes valores de dosagens de coagulante

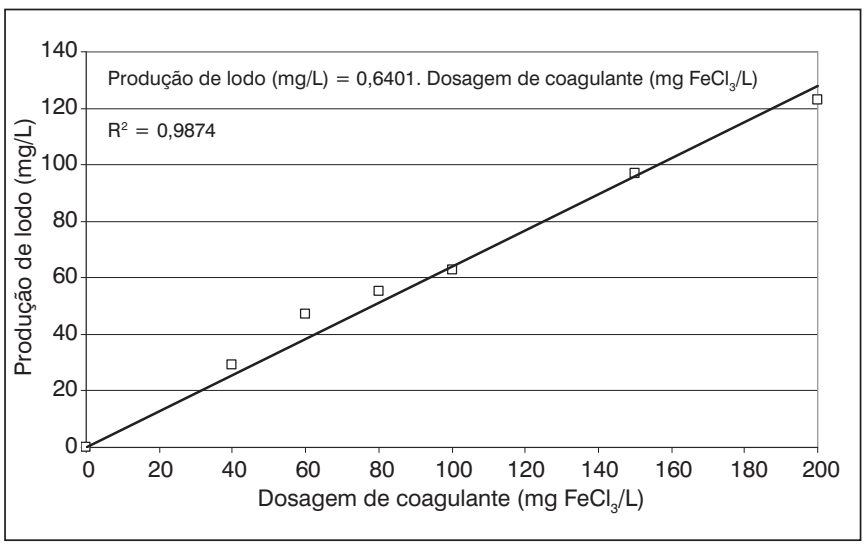

Figura 10 - Produção de lodo obtida para o Efluente Final Ribeirão Pires para diferentes valores de dosagens de coagulante

$\mathrm{Fe}^{+3}+3 \mathrm{OH}^{-}+n \mathrm{H}_{2} \mathrm{O} \rightarrow \mathrm{Fe}(\mathrm{OH})_{3} \cdot n \mathrm{H}_{2} \mathrm{O}$

Equação 6

A precipitação do ferro na forma de hidróxido férrico tende a ocorrer incorporando um número de moléculas de água de hidratação. Reporta-se na literatura que o valor de n pode variar de 1 a 3 .
Portanto, para cada $1 \mathrm{mg} \mathrm{Fe} / \mathrm{L}\left(2,90 \mathrm{mg} \mathrm{FeCl}_{3} / \mathrm{L}\right)$ adicionados na fase líquida, a formação de hidróxido metálico precipitado pode variar de 2,23 mg/L a 2,88 mg/L. Expressando-se a produção de lodo em função da dosagem de cloreto férrico, constata-se que para cada $1 \mathrm{mg} \mathrm{FeCl}_{3} / \mathrm{L}$, a formação de lodo poderá variar de $0,77 \mathrm{mg} / \mathrm{L}$ a $0,99 \mathrm{mg} / \mathrm{L}$.

A Equação 6 tem sido considerada adequada para o cálculo da estimativa da produção de lodo em processos de tratamento de água oriundos da precipitação de sais de ferro na forma de hidróxidos metálicos. No entanto, uma vez que esgotos sanitários brutos e tratados apresentam uma composição química mais complexa do que quando comparados a águas naturais que possam ser empregadas para abastecimento público, ressaltando-se uma maior presença de compostos orgânicos e inorgânicos que possam complexar os íons férricos, a geração de lodo pode apresentar diferente comportamento do que o previsto pela estequiometria apresentada na Equação 6.

Com base nos resultados típicos de produção de lodo dispostos nas Figuras 8 a 10, observa-se que há uma variação praticamente linear em função da dosagem de coagulante, ou seja, quanto maior a dosagem de coagulante, maior a sua produção de lodo. O aspecto mais importante a ser observado é que, com base nos valores dos coeficientes angulares das retas de regressão apresentadas nas Figuras 8 a 10, os valores médios de produção de lodo para o Esgoto Bruto Barueri, Efluente Tratado Barueri e Efluente Tratado Ribeirão Pires situaram-se em torno de $0,77 \mathrm{mg} / \mathrm{mg} \mathrm{FeCl}_{3}, 0,82 \mathrm{mg} / \mathrm{mg} \mathrm{FeCl}_{3}$ e $0,64 \mathrm{mg} / \mathrm{mg} \mathrm{FeCl}_{3}$ respectivamente, valores bastante próximos dos calculados com base na estequiometria de precipitação do ferro em meio aquoso (Equação 6).

Utilizando-se todos os ensaios experimentais conduzidos com os efluentes em questão, foram calculados os valores médios e desvios padrões associados aos valores normalizados de produção de lodo oriundo da precipitação do coagulante na forma de hidróxido metálico. Esses dados são apresentados na Tabela 1.

Observando-se os resultados calculados e apresentados na Tabela 1, nota-se que as médias dos valores de produção de lodo seco foram ligeiramente menores do que quando comparadas aos estimados com base na estequiometria da precipitação do ferro em meio aquoso. No entanto, se porventura for considerado o valor médio calculado acrescido do seu respectivo desvio padrão, observa-se que os valores teóricos são bastante próximos quando comparados aos valores calculados, o que justifica o uso de seus valores como uma estimativa segura da produção de lodo gerada em processos de precipitação química. Como o cálculo dos valores de produção de lodo em qualquer ETE deve ser feito com bastante segurança a fim de que os balanços de massa possam ser corretamente efetuados, bem como determinadas as respectivas vazões sólidas e líquidas afluentes e efluentes 
Tabela 1 - Valores normalizados de produção de lodo na forma de hidróxido metálico para os diferentes efluentes empregados na investigação experimental

\begin{tabular}{|c|c|c|c|c|c|c|}
\hline \multirow[b]{2}{*}{ Efluente } & \multicolumn{3}{|c|}{$\begin{array}{l}\text { Produção de lodo } \\
\text { (mg lodo seco/mg Fe }\end{array}$} & \multicolumn{3}{|c|}{$\begin{array}{l}\text { Produção de lodo } \\
\text { (mg lodo seco/mg FeCl }{ }_{3} \text { ) }\end{array}$} \\
\hline & $\begin{array}{c}\text { Esgoto } \\
\text { Bruto } \\
\text { Barueri }\end{array}$ & $\begin{array}{l}\text { Efluente } \\
\text { Tratado } \\
\text { Barueri }\end{array}$ & $\begin{array}{c}\text { Efluente } \\
\text { Tratado } \\
\text { Ribeirão } \\
\text { Pires }\end{array}$ & $\begin{array}{l}\text { Esgoto } \\
\text { Bruto } \\
\text { Barueri }\end{array}$ & $\begin{array}{l}\text { Efluente } \\
\text { Tratado } \\
\text { Barueri }\end{array}$ & $\begin{array}{c}\text { Efluente } \\
\text { Tratado } \\
\text { Ribeirão } \\
\text { Pires }\end{array}$ \\
\hline Valores teóricos & \multicolumn{3}{|c|}{2,23 a 2,88} & \multicolumn{3}{|c|}{0,77 a 0,99} \\
\hline Média & 1,80 & 1,95 & 1,34 & 0,62 & 0,68 & 0,46 \\
\hline Desvio padrão & 0,74 & 0,96 & 0,58 & 0,26 & 0,33 & 0,20 \\
\hline Número de dados & 18 & 18 & 18 & 18 & 18 & 18 \\
\hline
\end{tabular}

a cada unidade de processo, a determinação da massa de hidróxido gerada mediante adição do coagulante torna-se de suma importância.

Dessa forma, a produção geral de lodo gerada em um processo físico-químico, que envolve a adição de um coagulante à base de ferro e possui uma unidade de separação sólido-líquido, pode ser calculada da seguinte forma:

$P_{L}=Q \cdot\left[(2,23\right.$ a 2,88$\left.) \cdot D_{\mathrm{Fe}}+S S\right] \cdot 10^{-3}$

Equação 7

onde:

$\mathrm{P}_{\mathrm{L}}$ : produção de lodo seco em $\mathrm{kg} /$ dia;

Q: vazão afluente em $\mathrm{m}^{3} /$ dia;

$\mathrm{D}_{\mathrm{Fe}}$ : dosagem de sais de ferro, expresso como $\mathrm{Fe}^{+3} \mathrm{em} \mathrm{mg/L;}$

SS: concentração de sólidos em suspensão totais capturados na unidade de separação sólido-líquido em mg/L.

Recomenda-se sempre a execução de ensaios experimentais que permitam a quantificação da produção de lodo em processos físicoquímicos que envolvem coagulação química. No entanto, na ausência de dados e em face dos resultados apresentados, pode-se, mediante o emprego da Equação 7, obter uma estimativa bastante razoável da produção de lodo em unidades constituídas de processos que envolvem precipitação química por meio da adição de sais de ferro como coagulantes.

\section{Conclusões e recomendações finais}

Com base nos resultados experimentais, pode-se concluir que:

- considerando a necessidade do controle do $\mathrm{pH}$ em processos de remoção de fósforo por processos físico-químicos mediante adição de sais de ferro, torna-se de suma importância a avaliação temporal da variação da alcalinidade e pH do efluente, de modo que a adição do coagulante em suas dosagens adequadas não resulte em uma depleção em seu valor de pH, o que pode comprometer a eficiência do processo;

- caso os valores de alcalinidade inicial do efluente sejam iguais ou inferiores a $150 \mathrm{mg} \mathrm{CaCO}_{3} / \mathrm{L}$, deve-se prever a instalação de sistemas de dosagem de alcalinizantes juntamente com o coagulante, de modo que haja possibilidade de se garantir uma maior flexibilidade na operação do sistema de precipitação química;

- a redução da alcalinidade dos efluentes oriundos de processos biológicos aeróbios, quando se considera a sua nitrificação parcial ou total, justifica a necessidade de que sejam implantados sistemas de dosagem de alcalinizantes para a correção do $\mathrm{pH}$ do processo de coagulação química que objetiva a remoção de fósforo;

- os valores médios experimentais de produção de lodo resultante da formação do hidróxido férrico giraram em torno de 1,80; 1,95 e 1,34 mg lodo/mg Fe ${ }^{+3}$ para o Esgoto Bruto Barueri, Efluente Tratado Barueri e Efluente Tratado Ribeirão Pires, respectivamente, o que justifica o uso das Equações 6 e 7 para o cálculo da previsão de lodo gerados em sistemas de tratamento de esgotos que envolvem processos de precipitação química;

- embora se tenha empregado nos ensaios diferentes tipos de efluentes brutos e tratados, não se observou uma diferença significativa na produção de lodo resultante da formação de hidróxidos metálicos provenientes da adição do coagulante, o que indica que as características da fase líquida não influenciaram os mecanismos de precipitação dos íons férricos.

\section{Agradecimentos}

À Fundação de Amparo a Pesquisa do Estado de São Paulo (Fapesp) pelo apoio financeiro concedido (Processo 2006/55702-6) e bolsa de iniciação científica (Processo 2006/55703-2). 


\section{Referências}

APHA/AWW/WEF. Standard methods for the examination of water and wastewater. 21. ed. USA: APHA, 2005.

BENJAMIN, M.M. Water chemistry. New York: McGraw Hill, 2002.

MARAIS, G. Observation supporting phosphate removal by biological excess uptake: a review. Water Science \& Technology, v. 15, p. 15-41, 1983.

MULKERRINS, D.; DOBSON, A.D.W.; COLLERAN, E. Parameters affecting biological phosphate removal from wastewater. Environment International, v. 30, p. 249-259, 2004.

SANTOS, H.R. Coagulação/precipitação de efluentes de reator anaeróbio de leito expandido e de sistema de lodo ativado precedido de reator
UASB, com remoção de partículas por sedimentação ou flotação. Tese (Doutorado) - Escola de Engenharia de São Carlos da USP, São Carlos, 2006.

SEDLAK, R. Phosphorus and nitrogen removal from municipal wastewater: principles and practice. 2. ed. New York: Lewis Publishers, 1991.

SINELLI, P.H. Remoção de fósforo de efluente de tratamento anaeróbio por processo físico-químico. 128 f. Dissertação (Mestrado) - Escola Politécnica da USP, São Paulo, 2002.

SNOEYINK, V.L.; JENKINS, D. Water chemistry. New York: John Wiley \& Sons, 1980. 